\title{
CARBOXYHEMOGLOBIN LEVELS IN KENYAN CHILDREN WITH PLASMODIUM FALCIPARUM MALARIA
}

\author{
AUBREY J. CUNNINGTON, STUART F. W. KENDRICK, BETTY WAMOLA, BRETT LOWE AND \\ CHARLES R. J. C. NEWTON
}

Department of Paediatrics, Chelsea and Westminster Hospital, London, United Kingdom; Department of Medicine, University Hospital of North Durham, Durham, United Kingdom; Department of Paediatrics, Whittington Hospital, London, United Kingdom; Kenya Medical Research Institute Centre for Geographic Medicine (Coast), Kilifi, Kenya; Neurosciences Unit, Institute of Child Health, London, United Kingdom

\begin{abstract}
Heme oxygenase (HO) is thought to be induced in severe malaria, but the pathophysiologic consequences have not been examined. It is induced by hemolysis, oxidative stress, and inflammation. It degrades heme, producing carbon monoxide $(\mathrm{CO})$, which causes elevated levels of carboxyhemoglobin ( $\mathrm{COHb})$. In a prospective study of 1,520 children admitted to a Kenyan district hospital, $\mathrm{COHb}$ levels were no higher in children with malaria than with other infections. The COHb levels in children with severe malarial anemia were higher than in other children with malaria, but significantly lower than in children with other causes of severe anemia such as sickle cell disease. Levels of COHb were not significantly higher in children with cerebral malaria or in those dying of malaria. These results do not support a systemic increase in $\mathrm{HO}$ activity in malaria compared with other infectious diseases, but the roles of $\mathrm{HO}$ and $\mathrm{CO}$ in malaria require further study.
\end{abstract}

\section{INTRODUCTION}

It has recently been reported that expression of heme oxygenase-1 (HO-1) is increased in individuals dying of Plasmodium falciparum malaria. ${ }^{1-3}$ Heme oxygenase degrades heme, producing biliverdin, iron, and carbon monoxide $(\mathrm{CO})$, the latter binding to hemoglobin to form carboxyhemoglobin $(\mathrm{COHb}) .{ }^{4-6}$ Levels of $\mathrm{COHb}$ are raised in hemolytic diseases such as sickle cell disease $\mathrm{e}^{7,8}$ and were high in a single case of cerebral malaria. ${ }^{9}$ The roles of $\mathrm{HO}-1$ and $\mathrm{CO}$ are postulated to be protective because they have potent anti-inflammatory effects in diverse settings. Increased HO-1 expression reduces heme-induced inflammation ${ }^{10}$; HO-1 activity and $\mathrm{CO}$ inhibit the expression of lipopolysaccharide-induced proinflammatory cytokines and promote the expression of antiinflammatory cytokines ${ }^{11,12}$; $\mathrm{CO}$ rescues lung from damage by ischemia-reperfusion injury in HO-deficient mice, ${ }^{13}$ and human $\mathrm{HO}$ deficiency is characterized by vulnerability to oxidative and inflammatory damage, ${ }^{14}$ both of which occur in children with severe malarial anemia. ${ }^{15,16}$ However, the formation of $\mathrm{COHb}$ reduces the oxygen delivering capacity of blood and may aggravate tissue hypoxia and acidosis seen in severe malaria in children. Furthermore hemozoin, a polymer of sequestered heme produced by $P$. falciparum, is resistant to degradation by $\mathrm{HO}$ and may interfere with breakdown of hemoglobin. ${ }^{17}$

To investigate the role of $\mathrm{CO}$ in $P$. falciparum malaria, we measured concentrations of $\mathrm{COHb}$ in children admitted to hospital with malaria, and compared them to children admitted with other diseases and those who had recovered from malaria.

\section{MATERIALS AND METHODS}

From June 2001 through November 2001, 1520 children more than six months old were admitted to Kilifi District Hospital. Kilifi is located on the coast of Kenya, where malaria is holoendemic and almost exclusively caused by $P$. falciparum. The predominantly rural population of the area has been described elsewhere. ${ }^{18}$ Ethical approval was obtained from the Kenya Medical Research Institute ethics committee and children participated in the study after informed consent was obtained from a parent or guardian.

Demographic details, history, and examination findings by a clinician from the Kenya Medical Research Institute were recorded on a standardized proforma for all patients. Admission venous blood samples (prior to any blood transfusion) were examined for malaria parasites (thick and thin films stained with $10 \%$ Giemsa) and the number of pigment containing cells was counted in each of 200 monocytes, neutrophils, and erythrocytes. A full blood count using a Coulter Counter (MDII 18; Coulter Electronics, Ltd., Luton, United Kingdom) and venous blood gas analysis for $\mathrm{COHb}$, oxyhemoglobin $(\mathrm{OxyHb})$, reduced hemoglobin $(\mathrm{RHb}), \mathrm{pH}$, and base excess, using a co-oximeter (IL-682; Instrument Laboratory, Warrington, United Kingdom) were performed. Further investigations including radiology, cerebrospinal fluid analysis, bacterial cultures, repeat blood films, and hemoglobin electrophoresis were performed as necessary to reach a primary diagnosis for each patient.

A diagnosis of malaria was only made in children with a peripheral parasitemia and no other cause for the illness after review of all clinical and laboratory data. Severe malaria was defined as malaria with the presence of prostration, deep breathing, or severe malarial anemia (hemoglobin level $\leq 5$ $\mathrm{g} / \mathrm{dL}$ ). Cerebral malaria was defined by a Blantyre coma score $\leq 2$ or inability to localize a painful stimulus. ${ }^{19}$ All children were treated according to local guidelines. ${ }^{20}$ Additional diagnoses such as anemia or febrile convulsions contributing to the presentation, were recorded as secondary diagnoses.

An additional group of 50 children, who were well following outpatient treatment with lapudrine and dapsone for mild malaria, had hemoglobin and $\mathrm{COHb}$ concentrations measured at the same time that blood was taken on day 7 to confirm clearance of parasitemia. These children did not have quantitative assessment of malaria pigment on blood films.

Statistical analysis was performed using SPSS version 11.5 for the PC (SPSS, Inc., Chicago, IL). Central tendency for normally distributed variables was expressed as mean with standard deviation, and median with interquartile range for non-normal distributions. Student's $t$-test and one-way analysis of variance were used to compare means. Kendall's tau-b 
test (non-parametric) was used for all correlations. A $P$ value $<0.05$ was considered significant. Further analysis to determine the effect of covariates on $\mathrm{COHb}$ was performed using stepwise linear regression. The effect of dichotomous variables, adjusted for the influence of other fixed factors and covariates, was assessed using general linear model regression analysis. Covariates of interest were included in the first fit of the model if significantly correlated with $\mathrm{COHb}(P<0.10)$, then excluded stepwise if they failed to have a significant $(P<0.05)$ overall effect on the model.

\section{RESULTS}

Of 1,520 subjects, final diagnoses were available for 1,512, of whom $850(56.2 \%)$ had a diagnosis of malaria, $277(18.3 \%)$ had a diagnosis of anemia (Table 1), and 126 (8.3\%) had malaria with severe anemia. Some patients had more than one diagnosis, giving a total of 2,124 diagnoses. In 1,477 children $(97.2 \%)$, the level of $\mathrm{COHb}$ was $>2 \%$; the maximum reported for non-smokers in the United Kingdom. ${ }^{21}$ More than $90 \%$ of the children were anemic $(1,318$ of 1,464 children in whom hemoglobin concentration was measured; hemoglobin level $<11 \mathrm{~g} / \mathrm{dL}$ in children $<7$ years old and $<12 \mathrm{~g} / \mathrm{dL}$ in children $\geq 7$ years old).

There were significant positive correlations between $\mathrm{COHb}$ and age, spleen size, liver size, mean red blood cell volume, $\mathrm{OxyHb}, \mathrm{pH}$, and base excess (Table 2). There were significant inverse correlations between $\mathrm{COHb}$ and axillary temperature, white blood cell count, hemoglobin concentration, and $\mathrm{RHb}$. Although these correlations were statistically significant, most of the correlation coefficients were very low, suggesting that these factors explained little of the overall variation in $\mathrm{COHb}$. Carboxyhemoglobin was not significantly associated with conscious level, capillary refill time, or the proportion of malaria pigment-containing cells. Linear regression analysis showed that there were significant independent associations of $\mathrm{COHb}$ with age, hemoglobin concentration, mean red blood cell volume, $\mathrm{pH}, \mathrm{RHb}$, spleen size (all $P<0.001)$, and liver size $(P=0.007)$.

Mean $\mathrm{COHb}$ in children with malaria was not significantly different from children with other primary diagnoses except

TABLE 1

Carboxyhemoglobin $(\mathrm{COHb})$ levels in the most common clinical diagnoses*

\begin{tabular}{lrlcc}
\hline \multicolumn{1}{c}{$\mathrm{n}^{\dagger}$} & \multicolumn{1}{c}{$\begin{array}{c}\text { Mean COHb } \\
(95 \% \mathrm{CI})\end{array}$} & $\mathrm{SD}$ & $P \S$ \\
\hline Malaria & $850(689)$ & $4.08(4.00-4.18)$ & 1.44 & - \\
Anemia & $277(33)$ & $5.09(4.43-5.75)$ & 1.85 & 0.20 \\
Gastroenteritis & $181(89)$ & $3.83(3.53-4.14)$ & 1.37 & 1.00 \\
LRTI & $178(93)$ & $4.12(3.84-4.40)$ & 1.37 & 1.00 \\
Malnutrition & $150(81)$ & $4.05(3.77-4.32)$ & 1.24 & 1.00 \\
Febrile convulsion & $142(15)$ & $4.98(4.14-5.82)$ & 1.51 & 0.88 \\
Sickle cell disease & $32(22)$ & $6.56(5.71-7.41)$ & 1.91 & $<0.001$ \\
PUO & $29(27)$ & $4.15(3.58-4.74)$ & 1.48 & 1.00 \\
Soft tissue infection & $27(14)$ & $3.69(3.03-4.34)$ & 1.15 & 1.00 \\
Burns & $27(25)$ & $3.46(3.02-3.90)$ & 1.08 & 0.40 \\
Epilepsy & $24(16)$ & $5.09(4.32-5.86)$ & 1.44 & 0.54 \\
\hline
\end{tabular}

$* \mathrm{CI}=$ confidence interval; LRTI $=$ lower respiratory tract infection; $\mathrm{PUO}=$ pyrexia of unknown origin.

$\dagger$ Total. Values in parentheses are the number with a primary diagnosis only.

$\doteqdot$ For primary diagnosis only. test.

Compared with malaria by one-way analysis of variance using the post hoc Tamhane T2 patients with sickle cell disease, in whom $\mathrm{COHb}$ was significantly higher (Table 1). There was no significant difference in mean levels of $\mathrm{COHb}$ in children with parasitemia on admission $(\mathrm{n}=894$, mean $=4.22 \%, \mathrm{SD}=1.49 \%)$ compared with those without parasitemia $(\mathrm{n}=568$, mean $=4.15 \%, \mathrm{SD}=$ $1.57 \%$ ). Malaria pigment was assessed in 1,481 subjects and the mean $\mathrm{COHb}$ was not significantly different between those with detectable pigment $(\mathrm{n}=652$, mean $=4.16 \%$, SD $=$ $1.29 \%)$ and those without $(\mathrm{n}=829$, mean $=4.25 \%, \mathrm{SD}=$ $1.66 \%)$. The mean $\mathrm{COHb}$ was significantly $(P<0.001)$ higher in subjects with severe anemia $(\mathrm{n}=208$, mean $=4.81 \%$, $\mathrm{SD}=1.76 \%)$ than in those without severe anemia $(\mathrm{n}=$ $1,256$, mean $=4.10 \%, \mathrm{SD}=1.45 \%)$. Mean $\mathrm{COHb}$ in those with a primary diagnosis of severe malarial anemia $(\mathrm{n}=109$, mean $=4.43 \%, \mathrm{SD}=1.51 \%)$ was significantly $(P=0.012)$ lower than in those with severe anemia associated with other primary diagnoses $(n=67$, mean $=5.13 \%, \mathrm{SD}=1.89 \%)$. Mean $\mathrm{COHb}$ in jaundiced subjects $(\mathrm{n}=29$, mean $=5.52 \%$, $\mathrm{SD}=1.47 \%)$ was significantly $(P=0.002)$ higher than in those without jaundice $(\mathrm{n}=1,488$, mean $=4.19 \%, \mathrm{SD}=$ $1.50 \%$ ).

Malaria without other coexisting illness. Six hundred eighty-nine patients had a primary diagnosis of malaria and no other coexisting illness. Median age was 26 months (interquartile range $=16-42$ months) and $668(97.0 \%)$ had $\mathrm{COHb}$ levels $>2.0 \%$. The mean hemoglobin concentration was 7.64 $\mathrm{g} / \mathrm{dL}(\mathrm{SD}=2.37)$ and $109(16.3 \%)$ of 669 children were severely anemic. In these children, $\mathrm{COHb}$ was significantly correlated with spleen size, oxyHb, mean cell volume, and $\mathrm{pH}$ (all $P<0.001)$. There were inverse correlations of $\mathrm{COHb}$ with temperature $(P=0.044), \mathrm{RHb}$, hemoglobin concentration (both $P<0.001)$, white blood cell count $(P=0.008)$, and $\log$ (parasite density) $(P=0.033)$. There was no significant correlation between $\mathrm{COHb}$ and age, liver size, capillary refill time, conscious level, base excess, or proportion of pigment containing neutrophils, monocytes, or erythrocytes. Stepwise linear regression analysis showed that only hemoglobin concentration, mean red blood cell volume, $\mathrm{RHb}$, and $\mathrm{pH}$ were significantly (all $P<0.001$ ) independently associated with $\mathrm{COHb}$. Only six children with a primary diagnosis of malaria were jaundiced, with a mean $\mathrm{COHb}$ of $4.16 \%(\mathrm{SD}=1.30 \%)$, which was not significantly higher than in the other children with malaria $(\mathrm{n}=681$, mean $=4.08 \%, \mathrm{SD}=1.37 \%)$.

Severe malaria. The mean $\mathrm{COHb}$ of $4.31 \%(\mathrm{SD}=1.42 \%)$ in children with severe malaria was significantly higher $(P=$ $0.038)$ than in other children with malaria $(\mathrm{n}=566$, mean $=$ $4.01 \%$, SD = 1.36). The independent associations of the different manifestations of severe malaria with $\mathrm{COHb}$ were compared using general linear model regression analysis (Table 3). Severe anemia was associated with a significantly higher mean $\mathrm{COHb}$ and deep breathing was associated with a significantly lower mean $\mathrm{COHb}$. Mean levels of $\mathrm{COHb}$ in those with prostration, cerebral malaria, or dying of malaria were not significantly different from those in other children with malaria.

Adjusted analysis. To confirm that differences in $\mathrm{COHb}$ observed between groups were due to the diagnosis rather than other factors, further analysis was performed to adjust for the effect of significant laboratory and clinical variables. The covariates included in each initial model were age, $\mathrm{RHb}$, mean cell volume, and $\mathrm{pH}$. In models used to compare $\mathrm{COHb}$ between groups with different manifestations of malaria, log 
TABLE 2

Association of carboxyhemoglobin $(\mathrm{COHb})$ with clinical and laboratory characteristics in univariate analyses*

\begin{tabular}{|c|c|c|c|c|c|c|c|}
\hline & $\mathrm{n}$ & $\begin{array}{c}\text { Mean } \\
(95 \% \mathrm{CI})\end{array}$ & SD & Median & $\begin{array}{l}\text { Interquartile } \\
\text { range (range) }\end{array}$ & $\begin{array}{l}\text { Correlation } \\
\text { coefficient }{ }^{\dagger}\end{array}$ & $P$ \\
\hline Age (days) & 1,520 & & & 739 & $440-1367$ & 0.056 & 0.001 \\
\hline Temp $\left({ }^{\circ} \mathrm{C}\right)$ & 1,518 & $38.1(38.0-38.1)$ & 1.34 & & $37.1-39.1$ & -0.043 & 0.014 \\
\hline Spleen $(\mathrm{cm})$ & 1,520 & & & 0 & $0-1(0-20)$ & 0.099 & $<0.001$ \\
\hline Liver $(\mathrm{cm})$ & 1,520 & & & 0 & $0-0(0-10)$ & 0.040 & 0.047 \\
\hline Capillary refill (sec) & 1,520 & & & 1 & $0-2(0-9)$ & 0.005 & 0.79 \\
\hline BCS & 1,520 & & & 5.00 & $5-5(0-5)$ & -0.10 & 0.63 \\
\hline $\mathrm{COHb}(\%)$ & 1,520 & $4.21(4.13-4.29)$ & 1.52 & & $3.10-5.00$ & - & - \\
\hline RHb (\%) & 1,520 & & & 24.9 & $11.9-41.4$ & -0.316 & $<0.001$ \\
\hline OxyHb (\%) & 1,520 & & & 70.1 & $54.1-82.5$ & 0.265 & $<0.001$ \\
\hline $\mathrm{Hb}(\mathrm{g} / \mathrm{dL})$ & 1,464 & $8.03(7.90-8.15)$ & 2.53 & & $6.33-9.90$ & -0.172 & $<0.001$ \\
\hline MCV (fL) & 1,463 & $70.4(69.9-70.9)$ & 10.1 & & $63.1-76.2$ & 0.096 & $<0.001$ \\
\hline WCC $\left(10^{9} / \mathrm{L}\right)$ & 1,464 & & & 12.1 & $8.80-16.7$ & -0.065 & $<0.001$ \\
\hline Parasites $(/ \mu \mathrm{L})$ & 1,462 & & & 1,870 & $0-98,400$ & - & - \\
\hline $\begin{array}{l}\text { Pigment-containing } \\
\text { neutrophils }(/ 200)\end{array}$ & 1,479 & & & 0 & $0-2(0-64)$ & 0.004 & 0.853 \\
\hline $\begin{array}{l}\text { Pigment-containing } \\
\text { monocytes }(/ 200)\end{array}$ & 1,481 & & & 0 & $0-6(0-79)$ & -0.020 & 0.314 \\
\hline $\begin{array}{l}\text { Pigment-containing } \\
\text { erythrocytes }(/ 200)\end{array}$ & 1,474 & & & 0 & $0-0(0-179)$ & 0.016 & 0.446 \\
\hline $\mathrm{BE}(\mathrm{mEq} / \mathrm{L})$ & 1,467 & & & -7.70 & $-10.9-5.50$ & 0.045 & 0.012 \\
\hline $\mathrm{pH}$ & 1,467 & $7.35(7.34-7.35)$ & 0.095 & & $7.31-7.40$ & 0.158 & $<0.001$ \\
\hline
\end{tabular}

(parasite density) was also included as a covariate. No adjustment was made for hemoglobin concentration or spleen and liver size because our hypothesis was that hemolysis would be the main cause of any differences in $\mathrm{COHb}$. Adjusted analysis did not substantially change the results of any comparisons made with univariate analysis. However, if adjustment was also made for hemoglobin concentration, the mean $\mathrm{COHb}$ in severe malaria was not significantly different from that in other children with malaria, indicating that the degree of anemia accounts for the difference between these groups.

Comparison with control children. In 50 well and aparasitemic children who had completed outpatient treatment of mild malaria, the mean $\mathrm{COHb}$ was $1.13 \%$ ( $\mathrm{SD}=0.73 \%$ ), which was significantly lower than in subjects admitted to hospital with a primary diagnosis of malaria $(P<0.001)$. Only $4(8 \%)$ of these children had $\mathrm{COHb}>2 \%$. The mean hemoglobin concentration was $9.71 \mathrm{~g} / \mathrm{dL}$ and no children had se-

TABLE 3

Carboxyhemoglobin $(\mathrm{COHb})$ levels associated with clinical features in children with a primary diagnosis of malaria*

\begin{tabular}{lrcccc}
\hline & $\mathrm{n}$ & $\begin{array}{c}\text { Mean }(95 \% \mathrm{CI}) \\
\mathrm{COHb}\end{array}$ & $\mathrm{SD}$ & $P_{\dagger}^{\dagger}$ & $P \ddagger$ \\
\hline $\begin{array}{l}\text { Primary diagnosis of } \\
\quad \text { malaria }\end{array}$ & 689 & $4.08(4.00-4.18)$ & 1.44 & - & - \\
$\begin{array}{l}\text { Any features of severe } \\
\quad \text { malaria }\end{array}$ & & & & & \\
Severe anemia & 123 & $4.31(4.05-4.56)$ & 1.42 & - & 0.012 \\
Deep breathing & 109 & $4.43(4.15-4.72)$ & 1.51 & 0.001 & 0.040 \\
Prostration & 50 & $3.82(3.47-4.18)$ & 1.26 & 0.002 & 0.021 \\
Cerebral malaria & 107 & $4.27(3.98-4.56)$ & 1.51 & 0.092 & 0.350 \\
Death & 58 & $4.17(3.77-4.59)$ & 1.57 & 0.792 & 0.503 \\
& 12 & $3.97(3.00-4.93)$ & 1.52 & 0.842 & 0.632 \\
\hline
\end{tabular}

Death

$\mathrm{CI}=$ confidence interval

Using general linear model regression unadjusted for covariates.

Using general linear model regression with initial covariates: age, temperature, reduced hemoglobin concentration, mean cell volume, white cell count, log (parasite density), and $\mathrm{pH}$. vere anemia. Carboxyhemoglobin was not significantly correlated with hemoglobin concentration $(\mathrm{r}=-0.18, P=0.072)$.

\section{DISCUSSION}

Levels of $\mathrm{COHb}$ in this study of children admitted to a rural Kenyan hospital were uniformly increased compared with levels reported in studies of children and adults in the United States and the United Kingdom, and levels in children who had recovered from mild malaria. The mean $\mathrm{COHb}$ was $4.2 \%$, which was much higher than levels seen in American children (range $=0.6-3.9 \%$, mean $=1.3 \%$ ) and healthy, nonsmoking, adults in the United Kingdom (mean 1\%). ${ }^{7,21}$ However, within our study of inpatients, increased levels of $\mathrm{COHb}$ were not associated with parasitemia or a primary diagnosis of $P$. falciparum malaria, and this does not support greater induction of systemic HO-1 activity in malaria compared with other conditions. We were able to assess and adjust for the effect on $\mathrm{COHb}$ of a number of potentially important physiologic parameters, but in fact these had a negligible influence on the mean levels of $\mathrm{COHb}$ associated with different illnesses.

There are a number of possible explanations for the high overall levels of $\mathrm{COHb}$ in our population. Levels of $\mathrm{COHb}$ are determined by both endogenous and exogenous sources of $\mathrm{CO},{ }^{22}$ and environmental $\mathrm{CO}$ in smoke from traditional cooking methods can lead to high levels of $\mathrm{COHb},{ }^{23}$ although the levels were lower in children who had recovered from mild malaria. In west African adults, $\mathrm{COHb}$ concentrations even higher than those seen in our populations have been reported. ${ }^{24}$ In this study, $90 \%$ of the children were anemic and many children in this area of Kenya, even with iron deficiency anemia, have evidence of hemolysis and dyserythropoiesis, ${ }^{25}$ both of which would be expected to increase endogenous CO production. The majority of our patients had in- 
fectious illnesses requiring inpatient treatment and it is likely that some of the increased $\mathrm{CO}$ production was associated with sepsis. ${ }^{26}$ Although levels of $\mathrm{COHb}$ were not significantly different in patients with primarily non-infectious illnesses such as epilepsy or burns, it is possible in some cases that infection triggered seizures and that there was secondary infection or a systemic inflammatory response associated with severe burns. This perhaps explains why levels of $\mathrm{COHb}$ in children at the end of outpatient treatment of mild malaria, without an active systemic inflammatory response, were dramatically lower than in any of the groups of inpatients.

In those with malaria, levels of $\mathrm{COHb}$ were not significantly different from those with other infections such as lower respiratory tract infection, gastroenteritis, and soft tissue infections; results were compatible with malaria generating a similar inflammatory response to other infections. Most of the manifestations of severe malaria were not associated with significantly different levels of $\mathrm{COHb}$ except for deep breathing, in which lower levels of $\mathrm{COHb}$ were most likely as a result of high ventilation rate, ${ }^{22}$ and severe anemia, where higher levels were presumably due to hemolysis. However levels of $\mathrm{COHb}$ seen in subjects with malaria, and even severe malarial anemia, were considerably lower than in patients with sickle cell disease where the mean $\mathrm{COHb}$ of $6.56 \%$ is similar to values found in studies in the United States. ${ }^{8,27}$ This difference may be explained by the differences in hemolytic rate in each condition. In adults with severe $P$. falciparum malaria, the mean red blood cell lifespan has been shown to be approximately 40 days ${ }^{28}$ which is substantially longer than in sickle cell anemia where it may be only 10-20 days. ${ }^{29}$ The finding of increased expression of $\mathrm{HO}-1$ in the brains, lungs, and livers of individuals dying of malaria ${ }^{1-3}$ does not prove either systemic or local increases in HO-1 activity. It is possible for HO-1 to be induced but deprived of substrate, for example by sequestration of heme as hemozoin, or even for HO-1 activity to be inhibited. There is in vitro and in vivo evidence that hemozoin is resistant to degradation by HO-1 and its presence reduces $\mathrm{CO}$ production in mice with malaria. ${ }^{17,30}$ In our study, parasitemia was inversely correlated with $\mathrm{COHb}$ in children with malaria, and we found no correlation between $\mathrm{COHb}$ and circulating levels of malaria pigment.

Any degree of reduction in HO-1 activity could be important in the pathophysiology of malaria through loss of protection against oxidative damage, and loss of the antiinflammatory properties of $\mathrm{CO}$. A relative deficiency of HO-1 activity may contribute to the oxygen radical production and oxidative stress which damages erythrocyte membranes in severe malarial anemia. ${ }^{15,16}$ A reduction in CO production may promote the inflammatory process in severe malaria. It has recently been proposed that the combined action of $\mathrm{CO}$ and nitric oxide may be important in the development of tolerance to malaria by attenuating the systemic inflammatory response. ${ }^{31}$ Insufficient $\mathrm{CO}$ production may shift the balance in favor of the inflammatory cascade.

In summary, this study suggests similar levels of $\mathrm{HO}$ activity in malaria to those seen in other infections, as measured by levels of $\mathrm{COHb}$. Systemic levels of $\mathrm{COHb}$ in humans may not reflect $\mathrm{CO}$ production in individual tissues and further studies are warranted to determine whether there is a relative reduction in HO activity in malaria, which may be of importance in its pathogenesis.
Received February 16, 2004. Accepted for publication March 3, 2004.

Acknowledgments: We thank the Medical Officer of Health, the Medical Superintendent, the staff of Kilifi District Hospital, and N. Peshu (Director of the centre) for their support. This paper is published with the permission of the director of the Kenya Medical Research Institute.

Financial support: This study was supported by the Kenya Medical Research Institute and the Wellcome Trust. C. R. J. C. Newton is a Wellcome Trust Senior clinical fellow (050533).

Authors' addresses: Aubrey J. Cunnington, Department of Paediatrics, Chelsea and Westminster Hospital, 369 Fulham Road, London SW10 9NH, United Kingdom, E-mail: acunning@doctors.org.uk. Stuart F.W. Kendrick, Department of Medicine, University Hospital of North Durham, North Road, Durham, DH1 5TW, United Kingdom, E-mail: stuart.kendrick@doctors.org.uk. Betty Wamola, Department of Paediatrics, Whittington Hospital, Highgate Hill, London, N19 5NF, United Kingdom and Kenya Medical Research Institute, Centre for Geographic Medicine Research (Coast)/Wellcome Trust Research Unit, PO Box 230, Kilifi, Kenya, E-mail: bwamola@kilifi. mimcom.net. Brett Lowe, Kenya Medical Research Institute, Centre for Geographic Medicine Research (Coast)/Wellcome Trust Research Unit, PO Box 230, Kilifi, Kenya, E-mail: blowe@kilifi. mimcom.net. Charles R. J. C. Newton, Kenya Medical Research Institute, Centre for Geographic Medicine Research (Coast)/Wellcome Trust Research Unit, PO Box 230, Kilifi, Kenya and Neurosciences Unit, The Wolfson Centre, Mecklenburgh Square, London,WC1N 2AP, United Kingdom, E-mail: cnewton@kilifi.mimcom.net.

\section{REFERENCES}

1. Schluesener HJ, Kremsner PG, Meyerman R, 2001. Heme oxygenase-1 in lesions of human cerebral malaria. Acta Neuropathol (Berl) 101: 65-68.

2. Medana IM, Mai NT, Day NP, Hein TT, Bethell D, Phu NH, Farrar J, White NJ, Turner GD, 2001. Cellular stress and injury responses in the brains of adult Vietnamese patients with fatal Plasmodium falciparum malaria. Neuropathol Appl Neurobiol 27: 421-433.

3. Clark IA, Awburn MM, Harper CG, Liomba NG, Molyneux ME, 2003. Induction of HO-1 in tissue macrophages and monocytes in fatal falciparum malaria and sepsis. Malaria $J$ 2: 41.

4. Tenhunen R, Marver HS, Schmid R, 1969. Microsomal heme oxygenase. Characterization of the enzyme. J Biol Chem 244: 6388-6394.

5. Landaw SA, Callahan EW, Schmid R, 1970. Catabolism of heme in vivo: comparison of the simultaneous production of bilirubin and carbon monoxide. J Clin Invest 49: 914-925.

6. Coburn RF, Williams WJ, Forster RE, 1964. Effect of erythrocyte destruction on carbon monoxide production in man. J Clin Invest 43: 1098-1103.

7. Engel RR, Rodkey FL, Krill CE, 1971. Carboxyhemoglobin levels as an index of hemolysis. Pediatrics 47: 723-730.

8. Craft JA, Alessandrini E, Kenney LB, Klein B, Bray G, Luban NLC, Meek R, Nadkarni VM, 1994. Comparison of oxygenation measurements in pediatric patients during sickle cell crises. J Pediatr 124: 93-95.

9. Haynes JM, St. Pierre JT, 2000. Occult carboxyhemoglobinemia and hypoxemia in a patient with malaria. Respir Care 45: 115116.

10. Wagener FA, Eggert A, Boerman OC, Oyen WJ, Verhofstad A, Abraham NG, Adema G, van Kooyk Y, de Witte T, Figdor CG, 2001. Heme is a potent inducer of inflammation in mice and is counteracted by heme oxygenase. Blood 98: 1802-1811.

11. Otterbein L, Sylvester SL, Choi AMK, 1995. Hemoglobin provides protection against lethal endotoxemia in rats: the role of heme oxygenase-1. Am J Respir Cell Mol Biol 13: 595-601.

12. Otterbein LE, Bach FH, Alam J, Soares M, Tao Lu H, Wysk M, Davis RJ, Flavell RA, Choi AM, 2000. Carbon monoxide has anti-inflammatory effects involving the mitogen-activated protein kinase pathway. Nat Med 6: 422-428.

13. Fujita T, Toda K, Karimova A, Yan S-F, Naka Y, Yet S-F, Pinsky DJ, 2001. Paradoxical rescue from ischemic lung injury by in- 
haled carbon monoxide driven by derepression of fibrinolysis. Nat Med 7: 598-604.

14. Yachie A, Niida $Y$, Wada T, Igarashi N, Kaneda H, Toma T, Ohta K, Kasahara Y, Koizumi S, 1999. Oxidative stress causes enhanced endothelial cell injury in human heme oxygenase-1 deficiency. J Clin Invest 103: 129-135.

15. Kremsner PG, Greve B, Lell B, Luckner D, Schmid D, 2000. Malarial anaemia in African children associated with high oxygen-radical production. Lancet 355: 40-41.

16. Griffiths MJ, Ndungu F, Baird KL, Muller DPR, Marsh K, Newton CRJC, 2001. Oxidative stress and erythrocyte damage in Kenyan children with severe Plasmodium falciparum malaria. Br J Haematol 113: 486-491.

17. Schwarzer E, De Matteis F, Giribaldi G, Ulliers D, Valente E, Arese P, 1999. Hemozoin stability and dormant induction of heme oxygenase in hemozoin-fed human monocytes. Mol Biochem Parasitol 100: 61-72.

18. Berkley JA, Ross A, Mwangi I, Osier FHA, Mohammed M, Shebbe M, Lowe BS, Marsh K, Newton CRJC, 2003. Prognostic indicators of early and late death in children admitted to district hospital in Kenya: cohort study. BMJ 326: 361-364.

19. World Health Organization, 2000. Severe falciparum malaria. Trans $R$ Soc Trop Med Hyg 94 (Suppl 1): S1-S90.

20. Njuguna P, Newton CR, 2004. The management of severe malaria in children: a review. J Postgrad Med 50: 45-50.

21. Wald NJ, Idle M, Boreham J, Bailey A, 1981. Carbon monoxide in breath in relation to smoking and carboxyhaemoglobin levels. Thorax 36: 366-369.

22. Coburn RF, Forster RE, Kane PB, 1965. Considerations of the physiological variables that determine the blood carboxyhemoglobin concentration in man. J Clin Invest 44: 1899-1910.

23. Behera D, Dash S, Yadav SP, 1991. Carboxyhaemoglobin in women exposed to different cooking fuels. Thorax 46: 344-346.

24. Uko GP, Gbadebo JA, Banjoko SO, 1998. Carboxyhaemoglobin levels in some Lagos dwellers - a pilot study. West Afr J Med 17: 202-205.

25. Newton CRJC, Warn PA, Winstanley PA, Peshu N, Snow RW, Pasvol G, Marsh K, 1997. Severe anaemia in children living in a malaria endemic area of Kenya. Trop Med Int Health 2: 165-178.

26. Shi Y, Pan F, Li H, Pan J, Qin S, Jiang D, Shen C, 2003. Carbon monoxide concentrations in paediatric sepsis syndrome. Arch Dis Child 88: 889-890.

27. Sears DA, Udden MM, Thomas LJ, 2001. Carboxyhemoglobin levels in patients with sickle-cell anemia: relationship to hemolytic and vasoocclusive severity. Am J Med Sci 322: 345-348.

28. Looareesuwan S, Davis TM, Pukrittayakamee S, Supanaranond W, Desakorn V, Silamut K, Krishna S, Boonamrung S, White NJ, 1991. Erythrocyte survival in severe falciparum malaria. Acta Trop 48: 263-270.

29. Chen YH, Wang SC, 1985. A simple method for estimating the hemolytic rate in patients with sickle cell anemia. J Lab Clin Med 105: 201-208.

30. Eckman JR, Modler S, Eaton JW, Berger E, Engel RR, 1977. Host heme catabolism in drug-sensitive and drug-resistant malaria. J Lab Clin Med 90: 767-770.

31. Clark IA, Rockett KA, Burgner D, 2003. Genes, nitric oxide and malaria in African children. Trends Parasitol 19: 335-337. 